\title{
AVALIAÇÃO DA QUALIDADE FÍSICO-QUÍMICA DE DIFERENTES MARCAS DE CAFÉ TORRADO SOLÚVEL E EM PÓ COMERCIALIZADAS NA REGIÃO DO VALE DO TAQUARI/RS
}

\section{EVALUATION OF PHYSICO-CHEMICAL QUALITY OF DIFFERENT BRANDS OF ROASTED COFFEE SOLUBLE AND IN POWDER MARKETED IN THE REGION OF VALE DO TAQUARI/RS}

\author{
Ana Júlia Müller ${ }^{1}$; Luise Huebner ${ }^{2}$; Claucia Fernanda Volken de Souza ${ }^{3}$ \\ ${ }^{1}$ Centro Universitário UNIVATES - Lajeado - Brasil ana_ju_muller@yahoo.com.br \\ ${ }^{2}$ Centro Universitário UNIVATES - Lajeado - Brasil luise.huebner@ gmail.com \\ ${ }^{3}$ Centro Universitário UNIVATES - Lajeado - Brasil claucia@ univates.br
}

\begin{abstract}
Resumo
O Brasil é o maior produtor e exportador e o segundo maior mercado consumidor de café. Estudos apontam que o consumo regular de café pode auxiliar na prevenção da depressão e do consumo de drogas, principalmente devido à sua ação antioxidante. O café torrado é obtido a partir de frutos maduros de espécies do gênero Coffea, geralmente Coffea arábica L. e Coffea robusta L., que são submetidos à torrefação. $O$ objetivo deste estudo foi caracterizar físico-quimicamente diferentes marcas e lotes de café torrado em pó e solúvel. A qualidade do café foi avaliada através das seguintes análises físico-químicas: atividade de água, cafeína, cinzas, cinzas insolúveis em ácido clorídrico, extrato aquoso e umidade. De cada tipo de café foram analisadas três marcas e três lotes de cada marca. Os resultados encontrados para a maioria dos parâmetros avaliados atendem aos padrões estabelecidos pela legislação. Apenas na análise de cinzas os resultados encontrados estavam em desacordo com a legislação, com valores acima do limite de 5\% para as marcas A, B $e$ $C$ de café solúvel e para a marca $D$, de café em pó. A partir dos resultados obtidos pode-se evidenciar que algumas marcas de café comercializadas na região do Vale do Taquari não atendem aos padrões estabelecidos pela legislação.
\end{abstract}

Palavras-chave: café; físico-química; qualidade; legislação.

\section{Introdução}

O café torrado é obtido a partir do beneficiamento do fruto maduro de espécies do gênero Coffea, como por exemplo, Coffea arábica L., Coffea liberica Hiem e Coffea canephora Pierre (Coffea robusta Linden). O fruto é submetido a um tratamento térmico até atingir o ponto de torra escolhido (BRASIL, 1999). A produção brasileira de café nos últimos anos tem se destacado no 
contexto mundial. O Brasil é o maior produtor e exportador mundial e o $2^{\circ}$ maior mercado consumidor de café. Somente em 2010 o país produziu 48,095 mil sacas de $60 \mathrm{~kg}$, o equivalente a $36,08 \%$ da produção mundial, que foi de 133,308 mil sacas. A sua contribuição na exportação mundial representou, neste mesmo ano, 34,63\%. Ainda em 2010, o consumo da bebida no Brasil foi de 19,132 mil sacas de $60 \mathrm{~kg}, 47,32 \%$ do total consumido no mundo. Entre os anos de 2005 e 2010 o consumo da bebida no país aumentou em média 4,3\%, atingindo em 2010 um consumo per capita de 4,81 kg, uma marca histórica, superando o recorde de consumo nacional que foi de 4,72 $\mathrm{kg}$ per capita, em 1965. Pesquisas apontam que o café é, depois da água, a bebida de maior preferência no Brasil e que entre os brasileiros acima de 15 anos, 94\% a consomem (SOBREIRA, 2011; BERTONE, 2011).

Diversos estudos no Brasil e no exterior apontam que o consumo regular de café, até 4 xícaras diárias, é recomendado para jovens e adultos, podendo auxiliar na prevenção da depressão e do consumo de drogas. Isso porque a cafeína melhora o fluxo sangüíneo e atua no cérebro contrariando os efeitos da adenosina. Devido à ação antioxidante dos ácidos clorogênicos há a formação de quinídeos no processo de torra. Estes compostos formados bloqueiam o desejo excessivo de auto-gratificação que leva à depressão e ao consumo de drogas. Além disso, os quinídeos agem contra os efeitos da cafeína nas células nervosas e melhoram a microcirculação. A cafeína também estimula a vigília, a atenção, a concentração e a capacidade intelectual e os ácidos clorogênicos modulam o estado de humor, impedindo a depressão (LIMA, 2011).

De acordo com pesquisa apresentada pela Associação Americana para Pesquisa do Câncer, o consumo diário de café pode auxiliar no combate ao câncer de pele. Neste estudo houve uma redução de $20 \%$ em mulheres e $9 \%$ em homens que tomavam mais de três xícaras de café por dia, em relação a pessoas que haviam consumido menos do que uma xícara por mês. Não há certeza dos efeitos do café em relação ao câncer de pele, mas considera-se que a cafeína apresenta algum efeito inibitório sobre essa doença (CAFÉ, 2011).

Segundo Lima (2011), a maioria dos consumidores de café pensa que ele é constituído praticamente só por cafeína, desconhecendo quais são as substâncias presentes na bebida. $\mathrm{O}$ teor de cafeína no café é de 1 a 2,5\% e o restante é constituído por várias outras substâncias em maior quantidade, que podem até ser mais importantes para o organismo humano do que a cafeína. Dentre elas podem-se citar os ácidos clorogênicos, na proporção de 7 a 10\%. Em quantidades menores estão presentes uma grande variedade de minerais, aminoácidos, lipídeos, açúcares e vitaminas do complexo B (niacina).

No processamento para a obtenção dos cafés regular (em pó) e solúvel, as primeiras etapas coincidem. Inicia-se o processo com a limpeza dos grãos de café e procede-se a composição do "blend" do café: etapa em que é realizada a mistura das variedades de grãos de café utilizadas para 
que os padrões de cor e sabor sejam bem aceitos. Posteriormente, na torrefação, o café é aquecido até o ponto de torra. Nesta etapa o peso dos grãos é reduzido em 15 a 20\%, conforme o tipo de torra utilizado - fraca, média ou forte. Finalizada a torrefação, os grãos são moídos em espessuras que variam conforme o tipo de café. Para café regular (em pó) as partículas produzidas são mais finas, a fim de se obter maior superfície, e consequientemente maior rendimento de extração. Para o café solúvel os grânulos devem ser mais grossos, a fim de se evitar o entupimento de filtros. Após a moagem, o café está pronto para ser embalado a vácuo ou não, e comercializado (SEBRAE, 1999).

A qualidade do café está relacionada com o sabor e aroma do produto, sendo que estes sofrem influência de vários fatores tanto na pré como na pós-colheita. Entre os fatores de précolheita destacam-se o local do cultivo, o efeito das adubações, a quantidade de microorganismos presentes. Já para os fatores de pós-colheita destacam-se o armazenamento do café beneficiado, a torração do grão, entre outros fatores (CARVALHO; CHAGAS; SOUZA, 1997 apud HALAL, 2008).

O objetivo do presente estudo foi caracterizar físico-quimicamente diferentes marcas de café dos tipos em pó e solúvel comercializadas na região do Vale do Taquari no Rio Grande do Sul, comparando-as com os parâmetros estabelecidos pela legislação brasileira.

\section{Material e Métodos}

\section{Material}

O presente estudo baseou-se na avaliação de diferentes marcas de cafés torrados em pó e solúvel granulado comercializadas na região do Vale do Taquari/RS. Todas as amostras foram adquiridas em diferentes estabelecimentos comerciais da região.

De cada tipo de café foram analisadas três marcas e três lotes de cada marca, totalizando 18 amostras. As amostras foram genericamente denominadas A, B e C para o café solúvel granulado e A, D e E para o café em pó e os 3 lotes de cada marca foram denominados 1, 2 e 3.

\section{Métodos}

Para todas as amostras foram determinados a atividade de água (Aw) no equipamento AquaLab Decagon (CX-2) e os teores de umidade, cinzas, cinzas insolúveis em ácido clorídrico, extrato aquoso e cafeína, de acordo com as metodologias descritas no Manual do Instituto Adolfo Lutz (IAL, 2005).

A cafeína foi determinada pelo método espectrofotométrico. Realizou-se extração com clorofórmio, purificação inicial e quantificação por espectrofotometria na região ultravioleta a 274 
nm. O teor de cinzas foi encontrado através do resíduo resultante da incineração das amostras, aquecendo-as até temperatura próxima a $550-570{ }^{\circ} \mathrm{C}$, até o aparecimento de cinzas de coloração branca acinzentada. Para a determinação das cinzas insolúveis em ácido, o resíduo resultante da incineração das amostras foi tratado com $\mathrm{HCl}$ a $10 \%$, e novamente aquecido a $550{ }^{\circ} \mathrm{C}$. O extrato aquoso, que indica a quantidade de extrato solúvel do café, foi obtido através do método de extração à quente com água e o teor de umidade através da secagem direta em estufa a $105^{\circ} \mathrm{C}$.

Todas as análises foram realizadas em triplicata.

\section{Resultados e discussões}

Os resultados obtidos para as diferentes amostras de café em pó e café solúvel encontram-se nas Tabelas 1 e 2, respectivamente.

Tabela 1 - Resultados dos parâmetros físico-químicos das marcas de café em pó comercializadas no Vale do Taquari/RS

\begin{tabular}{cccccccc}
\hline MARCA & LOTE & Aw & $\begin{array}{c}\text { CAFEÍNA } \\
(\boldsymbol{\%})\end{array}$ & $\begin{array}{c}\text { CINZAS } \\
(\boldsymbol{\%})\end{array}$ & $\begin{array}{c}\text { CINZAS INSOLÚVEIS } \\
\text { EM HCl }(\boldsymbol{\%})\end{array}$ & $\begin{array}{c}\text { EXTRATO } \\
\text { AQUOSO }(\boldsymbol{\%})\end{array}$ & $\begin{array}{c}\text { UMIDADE } \\
(\boldsymbol{\%})\end{array}$ \\
\hline A & 1 & 0,394 & 5,1 & 4,5 & 0,1 & 35,2 & 2,3 \\
& 2 & 0,370 & 5,5 & 4,8 & 0,1 & 31,9 & 2,6 \\
& 3 & 0,344 & 5,8 & 4,9 & 0,1 & 33,7 & 2,1 \\
$\mathrm{D}$ & 1 & 0,323 & 4,9 & 5,0 & 0,3 & 31,2 & 1,8 \\
& 2 & 0,319 & 5,0 & 6,2 & 0,4 & 32,8 & 1,5 \\
& 3 & 0,346 & 5,4 & 5,8 & 0,2 & 44,1 & 1,3 \\
E & 1 & 0,367 & 5,0 & 4,7 & 0,1 & 35,6 & 2,8 \\
& 2 & 0,381 & 5,0 & 4,8 & 0,1 & 32,8 & 2,9 \\
& 3 & 0,365 & 4,8 & 5,0 & 0,2 & 37,2 & 3,0 \\
\hline
\end{tabular}

Tabela 2 - Resultados dos parâmetros físico-químicos das marcas de café solúvel comercializadas no Vale do Taquari/RS

\begin{tabular}{cccccccc}
\hline MARCA & LOTE & Aw & $\begin{array}{c}\text { CAFEÍNA } \\
(\boldsymbol{\%})\end{array}$ & $\begin{array}{c}\text { CINZAS } \\
(\boldsymbol{\%})\end{array}$ & $\begin{array}{c}\text { CINZAS INSOLÚVEIS } \\
\text { EM HCl }(\boldsymbol{\%})\end{array}$ & $\begin{array}{c}\text { EXTRATO } \\
\text { AQUOSO }(\boldsymbol{\%})\end{array}$ & $\begin{array}{c}\text { UMIDADE } \\
(\boldsymbol{\%})\end{array}$ \\
\hline A & 1 & 0,376 & 6,7 & 7,8 & 0,0 & 92,4 & 3,3 \\
& 2 & 0,479 & 6,8 & 9,0 & 0,5 & 96,3 & 2,7 \\
& 3 & 0,427 & 6,8 & 8,5 & 0,0 & 95,8 & 2,9 \\
B & 1 & 0,360 & 6,5 & 7,4 & 0,0 & 98,9 & 3,9 \\
& 2 & 0,421 & 6,5 & 8,6 & 0,0 & 98,1 & 3,9 \\
& 3 & 0,417 & 6,7 & 6,5 & 0,6 & 99,6 & 3,5 \\
C & 1 & 0,414 & 5,8 & 8,8 & 0,0 & 94,3 & 3,0 \\
& 2 & 0,461 & 5,7 & 9,7 & 0,0 & 99,3 & 2,5 \\
& 3 & 0,385 & 6,1 & 8,9 & 0,0 & 97,6 & 3,8 \\
\hline
\end{tabular}


As amostras de café solúvel também encontram-se dentro do padrão de 0,7\% para o teor de cafeína. Desta forma, todas as marcas estão em conformidade com a legislação, apresentando teores que variam de 5,7\% a 6,8\% de cafeína. Esta variação mais significativa pode ter ocorrido devido à composição da mistura inicial 'blend' ter sido diferente, já que nos grãos da espécie robusta a quantidade de cafeína é maior do que nos da espécie arábica (CAMARGO e TOLEDO, 1998). A marca $\mathrm{C}$ foi a que apresentou, na média, os menores teores de cafeína, de 5,7\% a 6,1\%. Considerando-se os três lotes de cada marca, a variação dos teores de cafeína entre eles foi baixa, indicando que a cafeína é bastante estável nas amostras produzidas em diferentes épocas do ano. Em um estudo realizado por Martins e Aquino (2008), analisando o café arábica, sendo submetido a torra média, obteve-se um teor de cafeína de 3,85\%.

Quanto ao teor de cinzas, para o café em pó apenas as marcas A e E encontraram-se dentro do padrão estabelecido pela legislação. A marca D, apresentou, nos lotes 2 e 3 resultados superiores a 5\%, o limite máximo permitido por lei (BRASIL, 1999). Os resultados foram, respectivamente 6,2 e $5,8 \%$ para os lotes 2 e 3 .

Em relação ao teor de cinzas, os resultados obtidos variaram de 6,5\% a 9,7\% nas três marcas de café solúvel, sendo todos acima de $5 \%$, ou seja, acima do limite preconizado pela legislação (BRASIL, 1999). Isso indica que há uma quantidade elevada de impurezas nas amostras e que sofreram alterações durante o processo produtivo (CECCHI, 2002). No estudo de Oliveira e Agostini (2009) todas as amostras avaliadas apresentaram teores de cinzas acima do limite máximo permitido, variando de 5,3 a 5,9\% nas 3 marcas. Segundo Cecchi (2002) esses resultados acima do padrão representam grande quantidade de impurezas ou sujidades nessas amostras, refletindo na sua qualidade. A presença de impurezas e sujidades nos cafés comercializados vem sendo bastante comum. Em estudo realizado por Barbieri e Yotsuyanagi (2002), cujo objetivo foi avaliar a qualidade higiênica de café em grãos e café torrado e moído de diferentes procedências, somente $7,8 \%$ das amostras atenderam aos limites estabelecidos pela legislação, sendo que foram analisadas 681 amostras de café em grãos e 580 amostras de café torrado e moído, de diferentes estados do Brasil. Esta não conformidade foi devido à presença de sujidades leves nas amostras, provenientes de insetos.

A determinação de cinzas insolúveis em ácido clorídrico indicou que todas as amostras de café em pó e solúvel analisadas continham teores aceitáveis, que não deve ser superior a $1 \%$ segundo a Portaria no 377 (BRASIL, 1999). A presença ou não de adulterações, devido a adição de minerais como areias, sujeiras, entre outros, em amostras de café pode ser detectada através da determinação das cinzas insolúveis em $\mathrm{HCl}$ (CECCHI, 2002). 
Os teores de extrato aquoso encontrados nas três marcas de café em pó variaram de 31,2 a $44,1 \%$. Desta forma, todas as amostras encontram-se dentro do padrão, que é de no mínimo $25 \%$ (BRASIL, 1999). No trabalho realizado por Licciardi et al. (2005) os valores de extrato aquoso variaram entre $25,00 \%$ e 38,98\%, também atendendo aos limites estabelecidos pela legislação. Já no estudo realizado por Martins e Aquino (2008) analisando o café arábica, submetido a torra média, obteve-se um extrato aquoso de 34,41\%. De acordo com Fernandes et al. (2003) a quantidade de substâncias que se solubilizam em água fervente são representadas pelo extrato aquoso, que pode ser alterado devido a adição de substâncias estranhas e minerais.

$\mathrm{Na}$ determinação do extrato aquoso das amostras de café solúvel obtiveram-se resultados acima de $25 \%$, indicando que todas as amostras atendem ao padrão estabelecido pela portaria (BRASIL, 1999). De acordo com Pedro et al. (1996), a variação nos teores de extrato aquoso é bastante comum, pois no café torrado e moído (em pó) os graus de torração e moagem podem variar conforme o processo utilizado. Além disso, também pode variar a composição do café, de acordo com as variedades utilizadas, aumentando ou diminuindo o teor de extrato aquoso. Segundo o estudo de Licciardi et al. (2005), o teor de extrato aquoso pode variar, inclusive, de acordo com a época da coleta das amostras do café. Em suas amostras, os teores de extrato aquoso variaram nas diferentes épocas do ano: em janeiro os teores variaram de $24,38 \%$ a $28,73 \%$, em abril a variação foi de $25,13 \%$ a $35,83 \%$ e em julho de $24,57 \%$ a $37,88 \%$. Considerando a média das variações, observa-se que os teores de extrato aquoso foram aumentando no decorrer dos meses.

Os teores de umidade das três marcas de café em pó analisadas estão dentro dos padrões da legislação, cujo limite máximo é de 5\% (BRASIL, 1999). No estudo realizado por Martins e Aquino (2008) foi analisado o café arábica, submetido a torra média, obtendo-se resultado de 3,5\% de umidade, que também se encontra de acordo com o padrão estabelecido pela Portaria $\mathrm{n}^{\circ} 377$. O teor de umidade do café pode afetar as características da amostra, a preservação do produto e principalmente o aroma, sendo um importante índice de qualidade. Se houvesse um teor de umidade elevado nas amostras, a atividade de micro-organismos e enzimas seria favorecida e as características sensoriais do produto seriam alteradas (MORGANO et al., 2008). Desta forma, em relação a estabilidade, qualidade e composição, pode-se dizer que as amostras de café solúvel analisadas não sofreram alterações no processamento, embalagem ou estocagem. $O$ trabalho de Oliveira e Agostini (2009) teve como objetivo avaliar físico-quimicamente amostras de cafés em pó produzidas e comercializadas em Dourados/MS visando investigar a qualidade destes produtos. Foram avaliadas no total três marcas diferentes, sendo três lotes de cada marca. Os parâmetros analisados foram umidade, resíduo mineral fixo, cinzas insolúveis em ácido clorídrico, determinação de extrato aquoso, determinação de extrato alcoólico e extrato etéreo. Das três marcas apenas uma (marca A) e todos os lotes desta estavam em conformidade com os padrões previstos 
pela legislação. As demais marcas, B e C, tiveram 1 e 2 lotes, respectivamente, fora do limite previsto na legislação. As não conformidades encontradas foram nos parâmetros de umidade, resíduo mineral fixo, cinzas insolúveis em ácido clorídrico, extrato alcoólico e extrato etéreo.

As três marcas de café solúvel analisadas e seus respectivos lotes apresentaram resultados de umidade dentro dos padrões estabelecidos pela legislação (BRASIL, 1999). Comparando-se as três marcas do café solúvel, os resultados de umidade não apresentaram variações altas, sendo de 2,5 a 3,9\%. Considerando cada marca separadamente, verificou-se que, em média, para a marca B os resultados foram os mais elevados - de 3,5 a 3,9\%. Já para as marcas A e C a variação entre os três lotes foi de 2,7 a 3,3\% e de 2,5 a 3,8\%, respectivamente. Como todas as marcas e seus respectivos lotes apresentam teores de umidade adequados, pode-se dizer que não sofreram alterações nos processos de estocagem, embalagem ou no processamento. Os baixos níveis de umidade de todas as amostras de café analisadas no presente trabalho e comercializadas na Região do Vale do Taquari/RS inibem o crescimento microbiano e, assim, evitam a deterioração do produto e prolongam a vida útil; além de minimizar o problema da presença de micotoxinas (JAY, 1996; FORSYTHE, 2002; DAMODARAN et al., 2010).

\section{Conclusões}

Baseando-se nos resultados obtidos para as diferentes marcas de café avaliadas, pode-se concluir que todas as marcas de café em pó e café solúvel apresentaram padrão físico-químico de acordo com o estabelecido na legislação brasileira, em relação aos seguintes parâmetros: umidade, extrato aquoso, cinzas insolúveis em ácido clorídrico e cafeína. Apenas os teores de cinzas apresentaram resultados acima do limite exigido pela legislação. Portanto, constatou-se que no Vale do Taquari/RS há a comercialização de cafés dos tipos solúvel e em pó que não apresentam a qualidade exigida em relação ao teor de impurezas.

\footnotetext{
Abstract

Brazil is the largest producer and exporter and second largest consumer of coffee. Studies show that regular consumption of coffee can help to prevent the depression and the drug use, mainly due to its antioxidant action. The roasted coffee is obtained from ripe fruits of the genus Coffea, usually Coffea arabica L. and Coffea robusta, which are subjected to roasting. The objective of this study was to characterize physical-chemically different brands and batches of roasted coffee in powder and soluble. The coffee quality was evaluated using the following physico-chemical analysis: water activity, caffeine, ash, ash insoluble in hydrochloric acid, aqueous extract and moisture. Of each type of coffee were analyzed three brands and three batches of each brand. The results for most
} 
parameters evaluated meet the standards set by legislation. Only the ash analysis results were in disagreement with the legislation, with values above the threshold of $5 \%$ for brands $A, B$ and $C$ of soluble coffee and for the brand $D$ of powder coffee. From the results obtained it is evident that some brands of coffee sold in the Vale do Taquari not meet the standards set by legislation.

Key-words: coffee; physico-chemical; quality; legislation.

\section{Referências}

BARBIERI, M. K.; YOTSUYANAGI, K. Avaliação da Qualidade Higiênica de Café Cru, Torrado e Moído de Diferentes Procedências. Brazilian Journal of Food Technology, v. 5, p. 101-107, 2002.

BERTONE, M. Brasileiros nunca consumiram tanto café como em 2010. Revista cafeicultura. Disponível em: $<$ http://www.revistacafeicultura.com.br/index.php?tipo=ler\&mat=38578\&brasileiros-nunca-consumiram-tanto-cafecomo-em-2010.html>. Acesso em: 18 nov. 2011.

BRAGA, G. C. et al. Variações de cor e de atividade de água Agaricus blazei desidratado e armazenado em diferentes embalagens plásticas. Acta Science Technology, v. 27, n. 1, p. 83-87, 2005.

BRASIL. Ministério da Saúde. Agência Nacional de Vigilância Sanitária. Portaria no 377, de 26 de abril de 1999. Estabelece normas para fixar a identidade e as características mínimas de qualidade do café torrado em grão e café torrado e moído. Diário Oficial da República Federativa do Brasil, Brasília, DF, 29 de abril de 1999, seção 1, n 80-E.

CAFÉ, Mais. Consumo de café pode reduzir o risco de câncer de pele - Outubro 2011. Revista cafeicultura. Disponível em: <http://www.revistacafeicultura.com.br/index.php?tipo=ler\&mat=42087\&consumo-de-cafepodereduzir-o-risco-de-cancer-de-pele--diz-pesquisa-.html>. Acesso em: 07 dez. 2011.

CAMARGO, M. C. R.; TOLEDO, M. C. F. Teor de cafeína em cafés brasileiros. Ciência e Tecnologia de Alimentos, v. 18, n. 4, 1998. http://dx.doi.org/10.1590/S0101-20611998000400012

CECCHI, H. M. Fundamentos teóricos e práticos em análises de alimentos. Campinas: Unicamp, 2002, 212 p.

DAMODARAN, S.; PARKIN, K.L.; FENNEMA, O.R. Química de alimentos de Fennema. 4 ed. Porto Alegre: Editora ArtMed, 2010, 900p.

FERNANDES, S. M. et al. Constituintes Químicos e Teor de extrato aquoso de Cafés Arábica (Coffea arabica L.) e Conilon (Coffea canephora Pierre) Torrados. Ciência e Agrotecnologia, v. 27, n. 5, p. 1076-1081, 2003. http://dx.doi.org/10.1590/S1413-70542003000500015

FORSYTHE, S.J. Microbiologia da Segurança Alimentar. Porto Alegre: Artmed, 2002.

HALAL, S. L. M. E. Composição, Processamento e Qualidade do Café. 2008. 45f. Bacharelado em Química de Alimentos. Universidade Federal de Pelotas, Pelotas. Disponível em:<http://quimicadealimentos.files.wordpress.com/2009/08/cafe.pdf>. Acesso em 7 dez. 2011.

IAL - Instituto Adolfo Lutz. Normas Analíticas do Instituto Adolfo Lutz: métodos químicos e físicos para análise de alimentos. v.1, 4 ed., São Paulo, 2005, 1018p.

JAY, J.M. Modern Food Microbiology. 5.ed. New York: Chapman \& Hall, 1996, 661p.

LICCIARDI, R.; PEREIRA, R. G. F. A.; MENDONÇA, L. M. V. L.; FURTADO, E. F. Avaliação físico-química de cafés torrados e moídos, de diferentes marcas comerciais, da região sul de Minas Gerais. Ciência e Tecnologia de Alimentos, v. 25, n. 3, p. 425-429, 2005. http://dx.doi.org/10.1590/S0101-20612005000300006

LIMA, D. R. Café e composição química. Associação Brasileira da Indústria de Café. Disponível em: <http://www.abic.com.br>. Acesso em 6 nov. 2011.

MARTINS, C. M; AQUINO, F. J. T. Estudo da composição química e da atividade antioxidante de cafés (Coffee Arábica) e de suas palhas provenientes do cerrado. Horizonte Científico, v. 2, n. 2, 2008. 
MORGANO, M. A.; FARIA, C. G.; FERRÃO, M. F.; BRAGAGNOLO, N.; FERREIRA, M. M. C. Determinação de umidade em café cru usando espectroscopia NIR e regressão multivariada. Ciência e Tecnologia de Alimentos, v. 28, n. 1, p. 12-17, 2008. http://dx.doi.org/10.1590/S0101-20612008000100003

OLIVEIRA, R. R.; AGOSTINI, J. S. Qualidade físico-química de diferentes marcas de cafés em pó, produzidos e comercializados em Dourados/MS. Interbio, v. 3, n. 2, p. 35-41, 2009.

PEDRO, N. A. R; BADOLATO, M. I. C.; FREITAS, V. P. S.; CHIARINI, P. F. T. Avaliação da qualidade do café torrado e moído processado na região de Campinas, estado de São Paulo. Revista do Instituto Adolfo Lutz, v. 56, n. 1, p. 113-117, 1996.

SEBRAE. Torrefação e moagem de café, 1999 disponível em: <http://www.biblioteca.sebrae.com.br/bds/BDS.nsf/84318D9DD46AEA548325742F0054016F/\$File/Torrefa\%C3\%A7 \%C3\%A3o\%20e\%20moagem\%20de\%20caf\%C3\%A9.pdf>. Acesso em: 18 nov. 2011.

SOBREIRA, M. Informe estatístico do café - Junho 2011. Revista cafeicultura. Disponível em: <http://www.revistacafeicultura.com.br/index.php?tipo=ler\&mat=40363\&informe-estatistico-do-cafe---junho-2011-8207-.html>. Acesso em: 18 nov. 2011.

Submetido em 02 mai. 2012, Aceito para publicação em 26 dez. 2012. 